\title{
Protein disulphide isomerase-assisted functionalization of proteinaceous substrates
}

\author{
MARGARIDA M. FERNANDES \& ARTUR CAVACO-PAULO
}

Textile Engineering Department, University of Minho, Campus of Azurém, 4800-058 Guimarães, Portugal

\begin{abstract}
Protein disulphide isomerase (PDI) is an enzyme that catalyzes thiol-disulphide exchange reactions among a broad spectrum of substrates, including proteins and low-molecular thiols and disulphides. As the first protein-folding catalyst reported, the study of PDI has mainly involved the correct folding of several cysteine-containing proteins. Its application on the functionalization of protein-based materials has not been extensively reported. Herein, we review the applications of PDI on the modification of proteinaceous substrates and discuss its future potential. The mechanism involved in PDI functionalization of fibrous protein substrates is discussed in detail. These approaches allow innovative applications in textile dyeing and finishing, medical textiles, controlled drug delivery systems and hair or skin care products.
\end{abstract}

Keywords: Protein disulphide isomerase (PDI), ribonuclease A (RNase A), keratin fibres, biotechnology, cosmetics

\section{Introduction}

Recent emphasis on environmentally friendly processes has led to increased use of enzymes for modification of polymeric and proteinaceous materials, as an alternative to conventional chemical methods. The advantages of enzymatic methods over chemical ones are high selectivity, ability to operate under mild conditions, catalyst recyclability and biocompatibility (Puskas et al. 2009).

Protein disulphide isomerase (PDI) is able to catalyze the modification of several proteinaceous substrates. It has been mainly studied for the folding, assembly and post-translational modification of polypeptides in the Endoplasmic reticulum (ER). However, applications outside of its in vivo function have not been extensively reported, so this review highlights applications of PDI as a bio-tool to target disulphide bond linkages. These linkages are of paramount importance in proteins, being responsible for the stabilization of protein structure (Wedemeyer et al. 2000) and in keratins, acting as a disulphide crosslinker that holds the cortical superstructure together (Plowman 2007).

We examine the published literature and (a) provide background on the chemistry of disulphide bond formation and rearrangement in proteins; (b) elucidate the structure of PDI, highlighting the important concept of redox potential; (c) detail the thiol-disulphide exchange reactions that are catalyzed by PDI in vitro; (d) and finally describe the PDI-assisted functionalization of keratinous fibres and proteinaceous substrates aiming cosmetic, textile and biomedical applications.

\section{Disulphide bonds and protein folding}

Understanding the role of disulphide bonds in protein folding is important to recognize the ability of PDI to functionalize proteinaceous substrates. The chemistry involved in the formation of disulphide bonds includes a two-electron reaction between two thiol groups $(-\mathrm{SH})$, which requires an oxidant or an electron acceptor. Disulphide bonds are formed spontaneously in vitro by the loss of electrons from two cysteine thiols coupled with the gain of electrons by an available acceptor, such as molecular oxygen. In vivo, however, the most common mechanism for disulphide bond formation is a thiol-disulphide exchange reaction between a free thiol and a disulphide-bonded species. This reaction may occur

Correspondence: Artur Cavaco-Paulo, Textile Engineering Department, University of Minho, Campus of Azurém, 4800-058, Guimarães, Portugal. Tel: +351253-510-271. Fax: +351-253-510-293. E-mail: artur@det.uminho.pt 
in the ER of eukaryotic cells or in the periplasmic space of prokaryotic cells, playing an important role in correct protein folding and stability (Sevier \& Kaiser 2002).

Disulphide bond formation is one of the key rate limiting steps in oxidative protein folding (Hatahet \& Ruddock 2009; Welker et al. 2001). The proximity, reactivity and accessibility of the disulphide bonds $(\mathrm{S}-\mathrm{S})$ and thiol groups $(-\mathrm{SH})$ have been identified as the three most important structural factors for proper folding of proteins and biological activity (Wedemeyer et al. 2000). Numerous studies agree that disulphide bonds play one of the most important roles in the folding process (Witt 2008). They are thought to control the conformational flexibility of unfolded proteins, decreasing conformational entropy and favouring the protein-folded state (Bulaj 2005; Jungbauer \& Kaar 2007). However, proteinfolding pathways are still the subject of much research and one of the major challenges in genetic and protein engineering (Freedman 1995). One theory relies on a funnel energy landscape concept (Bryngelson et al. 1995) that describes folding as the inevitable consequence of the requirement to lower the free energy (increased stability) as more native interactions are formed. In this view of folding (Figure 1), the denatured state of the protein populates a higher energy-state area in the funnel. The polypeptide chain may then fold by numerous pathways, potentially adopting multiple partially-folded ensembles en route to the native state, thus lowering the structure-energy (Onuchic \& Wolynes 2004). A protein can theoretically exist in a nearly infinite numbers of conformations along its energy landscape,

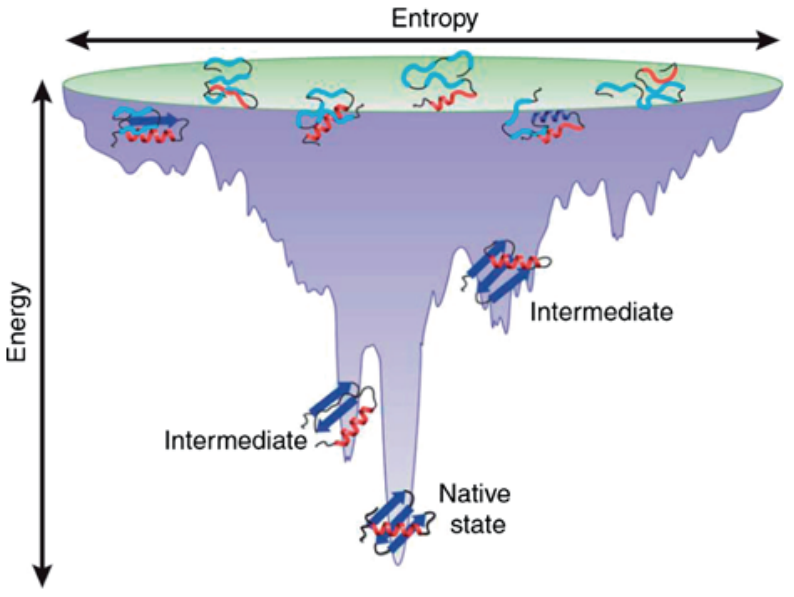

Figure 1. Schematic representation of a protein folding funnel energy landscape, adapted from Bartlett and Radford (2009). Nascent chain polypeptides can initially explore a wide range of conformations. Certain conformations occupy a lower energy state and are more stable, representing intermediates in the folding pathway. The native state is usually the lowest energy and most stable state. but in reality they fold into a unique conformation that possesses the lowest possible free energy (Anfinsen 1973). The ruggedness of the energy landscape arises from the fact that protein structures are stabilized by thousands of weak interactions that cannot all be satisfied simultaneously during folding (Bartlett \& Radford 2009). During the process, many metastable intermediates often include non-native interactions, which need to be overcome before the native state can be achieved (Hartl \& Hayer-Hartl 2002) (Figure 1).

It is known that, in vivo, correct protein folding is dependent on cellular catalysts that promote the formation of new disulphides (oxidation) and the rearrangement of non-native disulphide bonds (isomerization) and on chaperones to inhibit aggregation (Hartl \& Hayer-Hartl 2002; Kulp et al. 2006; Wang \& Tsou 1998). Early in folding, disulphide formation is error-prone and the protein-folding process may not occur properly (Wilkinson \& Gilbert 2004) due to the formation of incorrect cysteine linkages (Creighton 1979; Rothwarf et al. 1998), or that the correct cysteines are paired but in a temporal order that inhibits folding (Creighton 1992a; Weissman \& Kim 1991). This could cause the accumulation of misfolded proteins in the cell and lead to loss of function. This phenomenon is observed in a number of diseases (Dobson 2001; Thomas et al. 1995; Koo et al. 1999), including Alzheimer's (Harper \& Lansbury 1997), goiter (Kim et al. 1996), emphysema (Cabral et al. 2001) and prion infections (DebBurman et al. 1997). The eukaryotic cell, however, uses a number of mechanisms to protect against protein misfolding. These include chaperones and folding catalyst that inhibit aggregation and stimulate folding, such as PDI and specialized redox environments, such as the ER environment (Hwang et al. 1992; Fassio \& Sitia 2002).

\section{Protein disulphide isomerase}

First identified in 1963 and characterized based on its ability to catalyze the refolding of a protein with four disulphide bonds, the Ribonuclease A (RNase A) (Goldberger et al. 1963; Venetianer \& Straub 1963), PDI (E.C. 5.3.4.1) was later found to be a multifunctional enzyme able to catalyze disulphide bond formation, breakage and rearrangement. Playing a critical role in promoting native disulphide bond formation in vivo, PDI introduces disulphides into proteins (oxidase activity) and catalyzes the rearrangement of incorrect disulphides (isomerase activity). It recognizes a large number of cysteine-containing substrates including a multitude of native like, partially unfolded and non-native states (Wilkinson \& Gilbert 2004; Lyles \& Gilbert 1991; Gilbert et al. 1991; Freedman 
1995) and is thought to induce a state of lower energy on misfolded proteins, promoting their proper folding.

\section{PDI structure: domain organization and thioredoxin fold}

PDI from rat liver was first sequenced by Edman and co-workers, who found that this mature polypeptide in mammals had approximately 491 amino acids and a molecular weight of approximately $56 \mathrm{kDa}$ (Edman et al. 1985). This led to further analysis and definition of the modular structure of PDI. The analysis of its amino acid sequence revealed the multidomain nature of PDI in which four domains denoted $a, b$, b' and a', were identified (Edman et al. 1985). These four structural domains were followed by a stretch of acidic residues at the $\mathrm{C}$-terminus (designated c) (Figure 2).

From the DNA sequence information of the enzyme, two segments with homology to thioredoxin, a small ubiquitous protein that catalyzes reduction of protein disulphides, were identified (Holmgren 1985). These segments were defined as the catalytic active domains of PDI (a and a' domains, Figure 2), each possessing a Cys-Gly-His-Cys active-site motif (Wilkinson \& Gilbert 2004).

Although the two active sites can function independently, they do not have equivalent catalytic properties (Lyles \& Gilbert 1994). It has been reported that at a saturating concentration of substrate, the amino-terminal domain is capable of providing almost all of the catalytic activity for the oxidative refolding of reduced, denatured RNase A, while the carboxy-terminal domain contributes more to the steady-state binding of the substrate. However, at lower substrate concentrations (near $\mathrm{Km}$ ) both active sites contribute almost equally to catalysis (Walker et al. 1996).

The domains $\mathrm{b}$ and $\mathrm{b}^{\prime}$ (Figure 2) are similar in sequence to each other but not to thioredoxin and, therefore, are considered inactive. Studies have shown that ' $b$ ' domain is important in the overall catalytic ability of PDI, providing the principal peptide binding site of the enzyme (Klappa et al. 1998). In combination with a and a' domains, $b^{\prime}$ domains were found to be essential for simple isomerization reactions (Ellgaard \& Ruddock 2005). These studies indicated that a and a' domains are active domains responsible for the main PDI activities towards non-native proteins, whereas the b' domain contains a higher affinity binding site by which PDI holds substrates during isomerization reactions.

\section{The thioredoxin superfamily}

PDI is a member of a large family of dithiol/disulphide oxidoreductases, the thioredoxin superfamily. This family of thioredoxin-like enzymes includes prokaryotic enzymes, such as DsbA, DsbC, eukaryotic enzymes, such as Erp72, glutaredoxin, as well as the prototype of this family, thioredoxin (Ellgaard \& Ruddock 2005). These enzymes share the Cys-X1$\mathrm{X} 2$-Cys active-site motif and have a functional similarity: they are involved in sulfur-based redox reactions in the cell. During catalysis of disulphide formation in its substrates, PDI has two catalytically active thioredoxin domains while other family members have one (DsbA), two (ERp57), three (ERp72) (Mazzarella et al. 1990) or four (ERdj5) (Cunnea et al. 2003). The residues between the two active-site cysteines vary between each protein family and are important in determining the active-site potential and hence the physiological function of each enzyme. This can be modulated by mutations in the $\mathrm{XX}$ residues, which in part explains why enzymes with overall structural similarity can be reducing such as thioredoxin (Cys-Gly-Pro-Cys), highly oxidizing such as Dsba (Cys-Pro-His-Cys) or act as an isomerase such as PDI (Cys-Gly-His-Cys). PDI is the most versatile family member, capable of catalyzing oxidation, reduction and disulphide isomerization (Wilkinson \& Gilbert 2004).

\section{The catalytic domains of PDI and the redox potential}

The modulation of the redox potential of PDI is an important feature to understand the physiological relevance of the in vitro and in vivo reactions that PDI can catalyze. Each active site in a and a' domains of PDI contains two cysteines in the sequence CysGly-His-Cys that mediates all the activities of the enzyme. The cysteines in the form of vicinal thiol groups are essential for catalysis of redox reactions and can either form an intramolecular disulphide $(\mathrm{S}-\mathrm{S})$ or exist in dithiol form $(-\mathrm{SH})$.

The redox potential indicates the tendency of a chemical species to either gain or lose electrons when it is subject to a change by another molecule. It is an important characteristic that will define the propensity

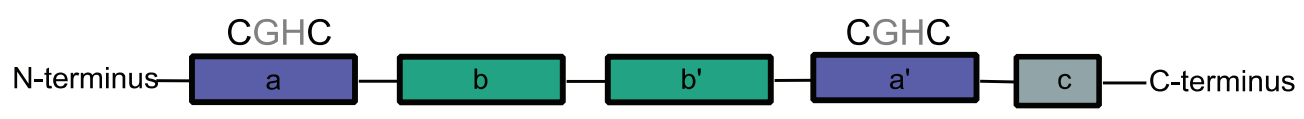

Figure 2. Domain organization of PDI. Catalytic domains a and a'; and non-catalytic domains b, b' and c. The active-site sequence of a and a' domains are also shown. 
of two thiols to form a disulphide bond or of an existing disulphide bond to be broken (Gough \& Lees 2005). The currently accepted redox potentials of various species, including a range of thioredoxinsuperfamily members are shown in Figure 3 (Åslund et al. 1997). These enzyme- properties are responsible for the highly reducing environment in the thioredoxin $\left(\mathrm{E}^{\circ}=-270 \mathrm{mV}\right)$ (Moore et al. 1964), the quite oxidizing one in $\operatorname{DsbA}\left(\mathrm{E}^{\circ}=-90\right.$ to $-110 \mathrm{mV}$ ) (Wunderlich \& Glockshuber 1993) and the intermediate redox potential in PDI $\left(\mathrm{E}^{\circ}=-180 \mathrm{mV}\right.$ ) (Wunderlich \& Glockshuber 1993; Lundstroem \& Holmgren 1993).

However, the redox potential of a species cannot be seen in isolation. By itself, the number is meaningless; it must always be seen in the context of a reaction with another species and the fact that is usually involved in an equilibrium reaction in which the relative concentrations of the species present plays a major role in the net reaction. PDI has a higher redox potential $\left(\mathrm{E}^{\circ}=-180 \mathrm{mV}\right)$ than the redox potential of denatured proteins and peptides $\left(\mathrm{E}^{\circ}=-200-220 \mathrm{mV}\right)$, and so it is expected to always promote the oxidation of the substrate, being reduced in the process (Hatahet \& Ruddock 2009). In this case, PDI would act as a protein dithiol-disulphide oxidant toward the denatured protein (Figure 4A). However, this is not always the case because of the influence of concentration on the net reaction.

The enzyme, thioredoxin, has the lowest redox potential of the thioredoxin superfamily members (i.e. it is the most reducing enzyme). Thermodynamically, it reduces disulphide bonds in proteins, and this is its primary physiological role in vivo (Lillig \& Holmgren 2007) because its redox potential is $\mathrm{E}^{\circ}=-270 \mathrm{mV}, 50 \mathrm{mV}$ lower than that of denatured proteins and peptides (Åslund et al. 1997). However, in vitro, it is able to catalyze the oxidation of dithiols to disulphides in folding proteins by using oxidized glutathione disulphide (GSSG) as the net electron acceptor (Figure 4B). Because of this, all thioredoxin-superfamily members have the potential to act as catalysts of protein-disulphide bond formation, reduction and isomerization.

The redox potential of these enzymes depends on the stability of the reduced $(-\mathrm{SH})$ and oxidized (S-S) state of the active site. Therefore, factors that stabilize the dithiol state of active site will lower the redox potential and thus make the enzyme a better reductant; the enzyme is destabilized by having the active-site dithiol, and so it is preferential to donate it to a non-native protein substrate (i.e. to reduce it). Similarly, factors that stabilize the disulphide state of PDI active site will increase the redox potential and will make the enzyme a better oxidant, and so it is preferential to take it from non-native protein substrates (i.e. to oxidize them) (Figure 5) (Wunderlich \& Glockshuber 1993).

The catalytic role of PDI is based on the following: when PDI catalyzes the oxidation of two cysteine thiol groups, it becomes reduced. Likewise, when

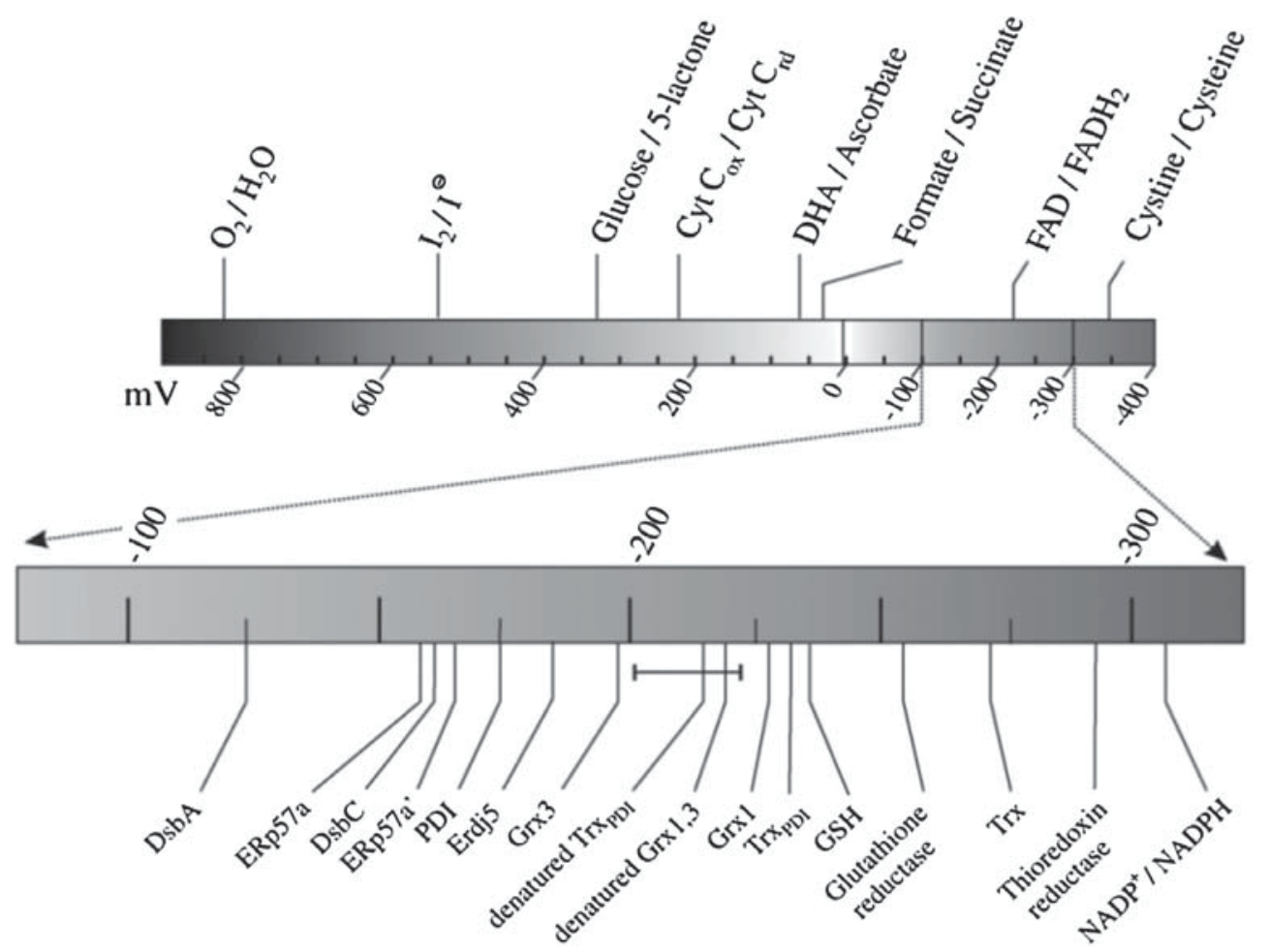

Figure 3. Biochemical standard redox potentials, including thioredoxin-superfamily members, adapted from (Åslund et al. 1997). 
A
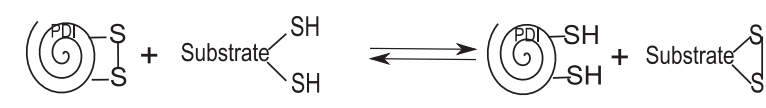

B

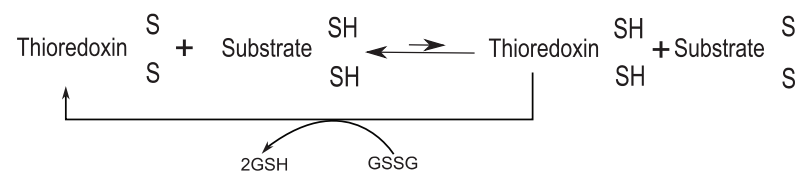

Figure 4. Catalysis of protein dithiol oxidation by (A) PDI, based on its redox potential $(-180 \mathrm{mV})$ and by $(B)$ thioredoxin also based on its redox potential $(-240 \mathrm{mV})$, and by using GSSG as the electron acceptor.

PDI catalyses the reduction of a disulphide bond, it becomes oxidized. To complete both catalytic activities, PDI must complete the cycle, that is, it should be re-oxidized when acting as an oxidase or re-reduced when acting as a reductase. For that, a redox generator such as glutathione should be present to act as an electron acceptor (GSSG-oxidase activity) or donor (GSH-reductase activity) (Hatahet \& Ruddock 2009) (Figure 5).

The presence of these species is used for redox modulation, to promote the active-site redox balance, mimicking the ER environment in vivo. The occurrence of glutathione in the ER provides a relatively reducing environment $(\mathrm{GSH} / \mathrm{GSSG}=3-5)$ (Hwang et al. 1992; Taniyama et al. 1990; Bass et al. 2004) that allows disulphide formation (oxidation) while maintaining sufficient reducing power to break incorrect disulphides.

Besides the amino-acid sequence of the PDI active site in a and a' domains and the equilibrium between the active-site cysteines on stabilizing the disulphide (oxidized) or dithiol (reduced) state, the other important factor that influence the redox potential of thioredoxin-superfamily members is the $\mathrm{pKa}$ of the active-site cysteine. One domain is located near the amino terminus while the second is located near the $\mathrm{C}$-terminus (Figure 2). The $\mathrm{N}$-terminal active-site cysteines are reported as having an unusually low $\mathrm{pKa}$, ranging from 4.4 to 6.7 , such that the active-thiolate state $\left(-S^{-}\right)$predominates at physiological pH (Hawkins \& Freedman 1991; Kortemme et al. 1996). Thiols of low pKa leave more rapidly

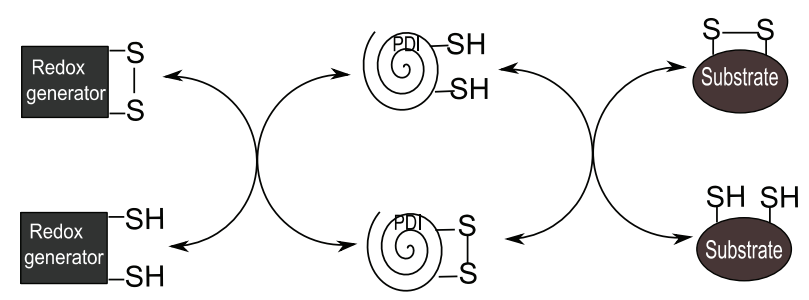

Figure 5. Enzymatic reaction catalyzed by PDI. The regeneration of the oxidoreductase can be accomplished by a small thiol buffer, such as glutathione. from a disulphide and are ionized more often, being therefore highly nucleophilic. Such an extremely low $\mathrm{pKa}$ value stabilizes the reduced state of PDI active site making the protein an excellent disulphide bond donor (Chivers et al. 1997). Therefore, when disulphides on active sites are reduced to the dithiol state, the cysteine residues present at the $\mathrm{N}$-terminal active site are predominantly in the thiolate $\left(-S^{-}\right)$state. These conditions provide a sufficiently high redox potential to allow efficient protein-dithiol oxidation and to have efficient kinetics for the initial steps of catalysis of thiol-disulphide exchange. The C-terminal active-site cysteines, however, are less reactive because they are buried and react only with the nucleophilic cysteine from the N-terminal (Walker et al. 1996) and are usually cited as having a high $\mathrm{pKa}$, such that the inactive thiol $(-\mathrm{SH})$ predominates at physiological pH (Hawkins \& Freedman 1991). The $\mathrm{pKa}$ values of cysteine residues thus play a crucial role in PDI-assisted disulphide bond formation. While thiols are weak nucleophiles, thiolates are more potent, and hence the kinetics of thiol-disulphide exchange is much faster once deprotonation of the cysteine side chain has occurred.

In summary, there are three prominent determinants of the redox potential of PDI to promote its enzymatic activity: the active-site sequence; the presence/absence of a redox generator that modulates the state of the N-terminal active site as disulphide $(\mathrm{S}-\mathrm{S})$ or dithiol $(-\mathrm{SH})$ and the $\mathrm{pKa}$ of the active-site cysteines that induce the presence of a reactive thiolate $\left(-S^{-}\right)$. Therefore, PDI allows predictions to be made about the types of reaction it performs.

\section{Catalysis of thio- disulphide exchange: isomerization}

PDI is one of the most abundant proteins in the ER, and it has been characterized as being mostly in its oxidized state (Frand \& Kaiser 1999), suggesting a primary role for its oxidase activity. In addition to its oxidase activity, evidence shows that the most important activity in vivo arises from its isomerase activity (Pollard et al. 1998). Disulphide formation that occurs early during protein folding is often prone to error, resulting in the pairing of two cysteines that are not connected in the native structure or in the paring of correct cysteines but in a temporal order that impedes further folding (Wedemeyer et al. 2000). When incorrect disulphides are formed, their isomerization is required to provide correct protein folding (Figure 6). This involves the breakage of a substrate disulphide and its reformation with different cysteines connected. The efficient action of PDI as an isomerase arises, in part, from the unusually low $\mathrm{pKa}$ of the $\mathrm{N}$-terminal active-site cysteine residues that initiates isomerization by attacking a substrate disulphide. 


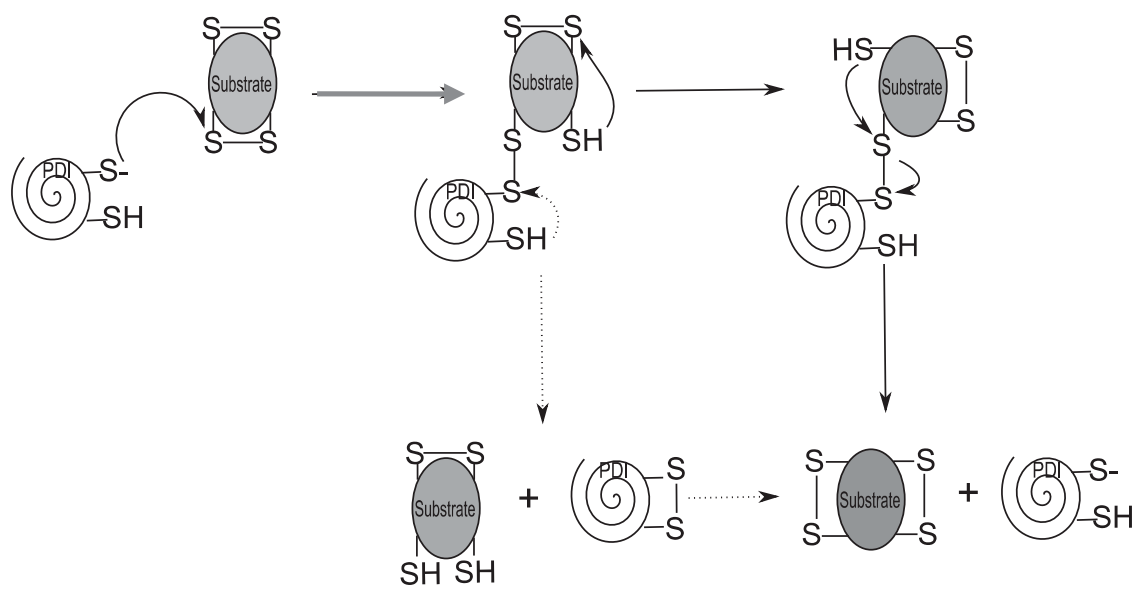

Figure 6. Mechanisms of PDI-catalyzed disulphide isomerization. Full arrow: in the intramolecular pathway, disulphide isomerization occurs through intramolecular rearrangement. Dotted arrow: the reduction oxidation pathway involves repeated cycling of substrate reduction and reoxidation in an alternative configuration.

After the initial reaction, two different mechanisms could result in substrate isomerization depending on how the covalent PDI-substrate intermediate reacts. In the first mechanism (Figure 6, full arrow) intramolecular rearrangement within the substrate may occur when the sulphydryl in the substrate cysteine, generated by PDI reacts with another disulphide from the substrate. In this mechanism, PDI facilitates intramolecular reactions between the thiols and disulphides of the substrate while the substrate is covalently bound to PDI. The intramolecular rearrangement is concluded with PDI displacement from the covalent complex and formation of another disulphide in the substrate together with the regeneration of reduced PDI for another round of catalysis. In the second mechanism (Figure 6, dotted arrow), PDI can resolve the covalent intermediate by reducing it. Cycles of substrate reduction and re-oxidation in a different configuration lead to isomerization, eventually leading to the native structure.

\section{PDI substrates and functions}

Many proteins have been identified as substrates for PDI in vitro, like soybean trypsin inhibitor (Steiner et al. 1965), insulin (Varandani \& Nafz 1970), immunoglobulins (Murkofsky \& Lamm 1979), vasopressin and oxytocin (Varandani et al. 1975), bovine serum albumin (Teale \& Benjamin 1976), cholera toxin (Moss et al. 1980), bovine pancreatic trypsin inhibitor (BPTI) (Creighton 1992b), ricin (Barbieri et al. 1982) and procollagen (Forster \& Freedman 1984). Besides catalyzing the oxidation, reduction or isomerization of disulphide bonds in a broad range of substrates, PDI also possess chaperone activity inhibiting aggregation of misfolded proteins and stimulating the correct folding, thus preventing serious diseases associated with protein misfolding (Hartl \& HayerHartl 2002).

All PDI substrates share one structural characteristic: the presence of cysteine residues. PDI is thought to be able to interact with a broad range of cysteinecontaining compounds (CCC) to promote oxidation of free thiols and reduction or isomerization of disulphide bonds. Keratin fibres and Ribonuclease A are examples of such compounds, and their structure, properties and applications will be elaborated below.

\section{Ribonuclease A}

Ribonuclease (RNase A) was used in the early studies of PDI refolding of non-native proteins to their native configuration (Goldberger et al. 1963; Venetianer \& Straub 1963). It is a small enzyme consisting of 124 amino acids with a molecular weight of $13.7 \mathrm{kDa}$ (Berisio et al. 2002; Raines 1998). Native RNase A in aqueous solution is a folded, monomeric protein with three $\alpha$-helices and six $\beta$-strands, the structure of which is stabilized by four disulphide bonds linking cysteines (Figure 7). It is one of the classic model systems of protein science and was the third protein to have its structure solved (Wyckoff et al. 1967). With several high-affinity binding sites, RNase $\mathrm{A}$ is a possible target for many organic and inorganic molecules (Neira et al. 1999; Leonidas et al. 2003). Various forms of this protein, including its oligomers, have been demonstrated for antitumor and other biological activities (Soucek et al. 1999; Matousek et al. 2003; Fu et al. 2004). The oxidative refolding of RNase A has been thoroughly investigated and led to the creation of the thermodynamic hypothesis of protein folding, which claims that the folded form of a protein represents the minimum of its free energy (Anfinsen 1973). 


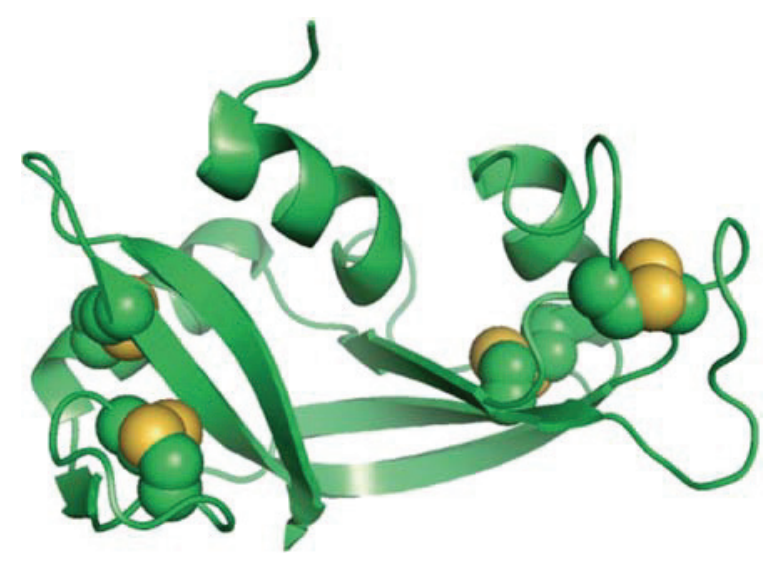

Figure 7. RNase A structure showing the three $\alpha$-helices, the six $\beta$-strands and the four disulphide bonds, represented by the yellow spheres, taken from protein data bank.

The PDI-induced refolding of RNase A microspheres developed by an ultrasonication methodology was the main objective of a recent study (Fernandes et al. 2011c). Application of ultrasound was shown to cause loss of 35\% of RNase A enzymatic activity, probably due to the breakage of disulphide bonds, and PDI was able to restore it. Furthermore, the application of PDI on a RNase A microspheres emulsion, in the presence of an appropriate oxidative environment, suggested that the refolding of microspheres into the aqueous medium was occurring (Fernandes et al. 2011c). The novelty of this study relies on the fact that biologically active RNase A microspheres may have potential application as an anti-tumour and immunosuppressive agent, as reported for several of its oligomers (Fu et al. 2004; Matousek et al. 2003). Moreover, the ultrasonication method is a low-cost and highly efficient one-step procedure, compared to the miniemulsion polymerization method (Tan \& Tong 2006), that produces particles at high concentrations with high stability and long shelf life (Gedanken 2008).

Novel approaches involving PDI for the development and functionalization of microspheres/nanoparticles may serve as the basis for advanced strategies in the stabilization of particle structures or as an agent to induce redox activated cleavage of disulphide bonds in particles. The development of redox sensitive, disulphide-based carrier systems is an important approach when considering the redox-potential gradient between extra- and intracellular environments. Outside cells, disulphide bonds provide high stability to the delivery system, but these are rapidly cleaved inside cells, facilitating the release of therapeutic molecules (Bauhuber et al. 2009).

\section{Keratin fibres}

Keratins belong to the family of fibrous structural proteins and are the basic building blocks of fibres such as hair and wool and the key structural materials of the outer layer of human skin and nails (Plowman 2007). They are complex natural composites with a heterogeneous, mostly proteinaceous (95\%-97\%) morphological structure, with structural lipids, pigment and other materials representing the remaining fractions (Heine \& Höcker 1995).

Being of biological origin, unlike synthetic polymer fibres, keratin fibres are not formed of chemically homogeneous fibre-length polypeptides, but a complex mixture of widely different polypeptides (Rippon 1992). The individual polypeptide chains are held together in many different ways, including covalent bonds, such as disulphide and isopeptide crosslinks, to weaker interactions such as hydrogen bonds, coloumbic, Van der Waals and hydrophobic interactions. Thus, the reactivity of keratins is complex and depends not only on the presence of reactive groups in the fibre, but also on their availability. The latter is significantly affected by fibre morphology and molecular structure (Wolfram 2003).

Three distinct types of cell are produced at the follicle base, which eventually produce the three basic components of the fibre structure: the multicellular external cuticle sheath, the fibrous cortex and the medulla (Franbourg et al. 2003; Wolfram 2003). A single layer of cells gives rise to the cuticle, a protective layer covering the core of the fibres. It is mainly composed of $\beta$-keratin and displays a scaled structure with the cuticle edges pointing toward the tip of the fibre (Swift 1999; Koehn et al. 2010). The outer surface of the cuticle scale cells is coated by a thin membrane called the epicuticle that covers the exocuticle, a constituent that contains most of the cysteine residues present in the scales (Feughelman 1997) (Figure 8). The endocuticle, located at the interface of the cortex, is mainly composed of the residual cell organelles and consists of proteins that, unlike those found in other parts of the keratin fibre, have very low sulfur content and thus poor in cysteine, which causes the endocuticle of the scales

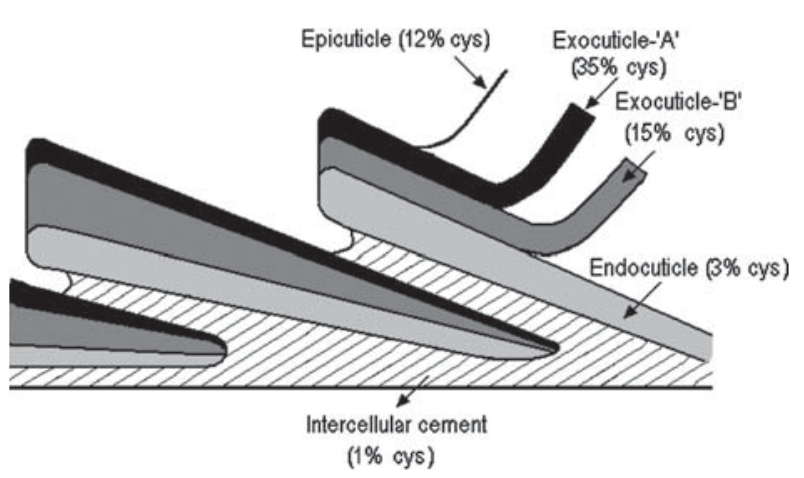

Figure 8. Schematic scale structure of the cuticle showing the major components, adapted from (Feughelman 1997). 


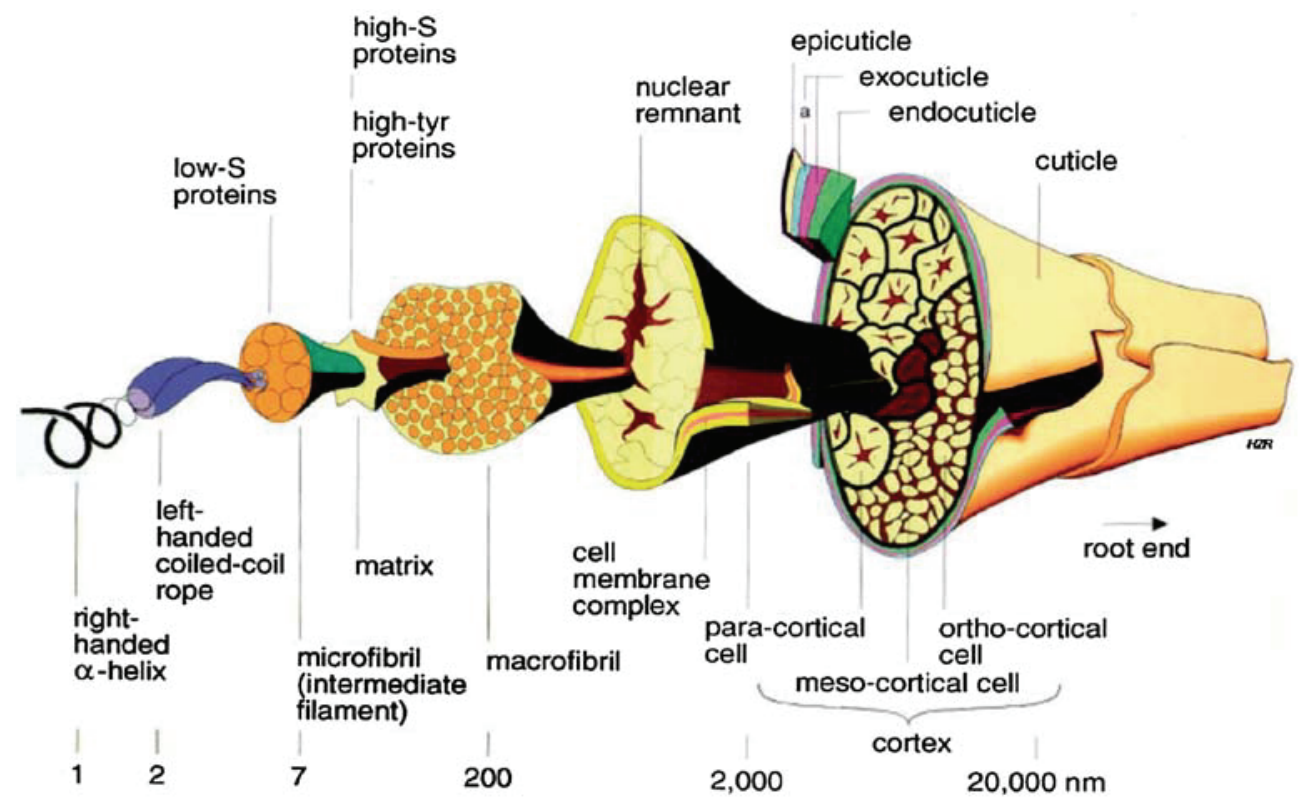

Figure 9. Cross-section diagram of a keratin fibre showing the structure at progressive magnifications, according to Feughelman (1997).

to swell considerably more in water then the cysteinerich exocuticle (Figure 8). This might explain the pronounced projection of the scales and the tendency for wool felting in the presence of water (O'Connor et al. 1995).

The cuticle tightly encircles the cortex that forms the most voluminous part of the keratin fibre. The cortex is made of cortical cells that comprises the macrofibrils, long filaments oriented parallel to the axis of the fibre. Each macrofibril consists of proteins called the intermediate filament proteins (IFPs), known also as microfibrils and the intermediate filament associated proteins (IFAPs), also known as matrix (Plowman 2007; Bhushan 2008) (Figure 9). It has been established that the molecules that aggregate to form the IFPs in keratin fibres are Type I and Type II keratin chains, arranged parallel to one another and in the axial register. After the formation of the $\alpha$-helices, it is believed that the two types of chain associate to form a dimer that then aggregates with another dimer to form a tetramer. Finally, the formation of a pseudo-hexagonal structure (the IFP's structure) occurs by association of seven or eight tetramers. Type I chains are net acidic, with $\mathrm{pI}$ values in the range of 4.5-5.5, while type II are neutral-basic with pI around 6.5-7.5 (Smith \& Parry 2007; Zimek \& Weber 2006; Parry et al. 2006; Jones et al. 1997).

The intermediate filaments are low in cystine $(\sim 6 \%)$ while the matrix contains up to $20 \%$ of total amino acid residues (Wysocki et al. 1954; Wilson \& Lewis 1927; Block et al. 1939). The matrix proteins, that is, IFAPs, are rich in cysteine and thus link through intermolecular disulphide bonds to IFPs, holding the cortical superstructure together and conferring high mechanical strength, inertness and rigidity to keratin fibres. High sulphur proteins, ultra-high sulphur proteins and high glycine-tyrosine proteins are present in matrix proteins ( $\gamma$-keratins), depending on their cysteine, tyrosine and glycine content (Figure 9) (Danciulescu et al. 2004; Feughelman 1997; Plowman 2003; Franbourg et al. 2003). Vacuolated cells may also be present along the axis of coarser $\alpha$-keratin fibres, forming the medulla. These cells generally constitute only a small percentage of the mass of keratin fibres and are believed to contribute negligibly to the mechanical properties of keratin fibres. Physically, the medulla forms the empty space of the fibre (Feughelman 1997; Bhushan 2008).

The reported biological activity and biocompatibility of keratins has been explored in the development of keratin-based materials with applications in wound healing, drug delivery, tissue engineering, trauma and medical devices (Rouse \& Van Dyke 2010; $\mathrm{Li}$ et al. 2007; Sierpinski et al. 2008). The high content of cysteine residues leads to a high rate of crosslinking through disulphide bonds (Franbourg \& Leroy 2005), explaining the high stability of the macrostructure of keratin fibres, and imparting good mechanical, thermal and chemical properties (Wilson \& Lewis 1927; Wysocki et al. 1954; Block et al. 1939). Keratins can be isolated from human or animal hair by controlling the conditions that lead to disulphide bonds scission and re-formation, and further fabricated into various designs, such as 
films (Vasconcelos et al. 2008; Tanabe et al. 2004; Yamauchi et al. 1996; Fujii et al. 2004), microcapsules (Yamauchi \& Khoda 1997), sponges and scaffolds (Katoh et al. 2004; Tachibana et al. 2005; Kurimoto et al. 2003).

Besides the biomedical field, keratins have a multitude of other applications. The use of keratin from feather meal has been investigated as a slow nitrogenrelease fertilizer, due to its slow decomposition rate (Hadas \& Kautsky 1994; Riffel \& Brandelli 2002; Brandelli et al. 2009). Also, the possibility of using keratin as a foaming agent for fire extinguishers, taking advantage of the protein biomass available as waste from the textile industry and butchery, has been reported (Zoccola et al. 2009; Kittle 1998; Hoshino et al. 1978).

Knowledge of the chemical structure of keratins allows for the development of new technologies for application in the textile and cosmetic industries. Regarding cosmetics, as well as understanding the hair surface as a substrate for functionalization, the application of new hair care products that contain keratin-based compounds, such as hydrolysate or fragments, has been reported (Barba et al. 2009; Cavaco-Paulo \& Silva 2007; Pille et al. 1998; Negri et al. 1993), although not extensively explored.

\section{PDI-assisted functionalization of wool}

The most characteristic structural feature of wool fibres, the high content of disulphide bonds (Bradbury 1973), has been poorly explored for enzymatic modification. The surface of wool should be susceptible to modification with enzymes active towards disulphide bonds, such as PDI.

Some studies have reported PDI treatment of wool fibres. King and Brockway (1992) showed that PDI was able to partly restore the original properties of harshly treated wool. The application of PDI was made in the presence of a cofactor comprising a low molecular weight thiol, such as dithiothreitol or reduced glutathione. These cofactors were essential for the action of PDI on the 'rejuvenation' of the fibres. Wool mainly comprises keratin, which undergo denaturation when aged or ill-treated, resulting in the disruption of disulphide bonds between cysteine residues. As a catalyst of disulphide-bond formation and isomerization, PDI was able to recover part of the physical properties of shrunken wool.

The functionalization of wool was also investigated by Fernandes et al (Fernandes et al. 2011b) for different applications, through modulation of the PDI active site (Figure 10). Figure 10 illustrates two possible reactions based on the state of the PDI active site. When the active site was set in its oxidized form, PDI was able to catalyze the formation of disulphide bonds and CCCs were, therefore, incorporated on to keratins. The release of the CCCs (disulphide scission), however, required PDI with its active site in the reduced form. A novel strategy for functionalization of keratinous fibres based on the ability of PDI to catalyze formation and scission of disulphide bonds between substrates and functional molecules was developed in this study.

The incorporation of a cysteine-containing dye on wool was demonstrated by MALDI-TOF analysis, after digestion of wool with a protease. Higher molecular weight fragments observed in the samples of the wool dyed in the presence of PDI suggested that disulphide bonding might have occurred, since proteases do not cleave disulphide bonds (Fernandes et al. 2011b). Therefore, the cysteine residues of wool apparently linked to the cysteine group from the dye would remain intact and not hydrolysed by proteases. The reason for the disulphide bond formation by PDI lies in the intrinsic redox potential $\left(\mathrm{E}^{\circ}=-180 \mathrm{mV}\right)$ used in this study, that stabilizes the oxidized form of the enzyme active site, promoting catalysis of the oxidation reaction (Figure 10, incorporation). The redox potential of PDI is higher than the redox potential of cystine/cysteine $\left(\mathrm{E}^{\circ}=-340 \mathrm{mV}\right)$, which favoured the oxidation of cysteine residues between dye and wool.

In this case, the use of PDI established a new enzymatic approach for application on wool fibres. Previously, other enzymes such as modified proteases and transglutaminases have typically been used for wool functionalization, usually targeting the surface cuticle scales (Dybdal et al. 2001; Mcdevitt et al. 1999; Silva et al. 2005; Silva et al. 2006; Silva et al. 2004; Cavaco Paulo \& Dos Santos 2006; Araújo et al. 2009; Cortez et al. 2004, 2005). The application of PDI to attach cysteine-containing compounds via disulphide bonds, combined with other enzymes to prevent unwanted effects on wool may therefore constitute an interesting approach for textile dyeing and finishing.

The contribution of the reduced form of PDI active site to the release of a protein, namely RNase A, previously attached to the wool surface by disulphide bonds, was also reported in this study (Figure 10, release). In this step, PDI was applied to modulate the scission of disulphide bonds created between the cysteine residues of the wool surface and those of RNase A, acting, therefore, as a switch-on agent for protein release (Figure 11). The application of a redox potential of $\Delta \mathrm{E}=-260 \mathrm{mV}$ promoted the reduction and/or the isomerisation of disulphide bonds (thiol/disulphide interchange reactions) catalyzed by PDI, which was thought to be the reason for the protein release. As a general perspective, this suggests that PDI could be used to trigger the selective release of active compounds. 

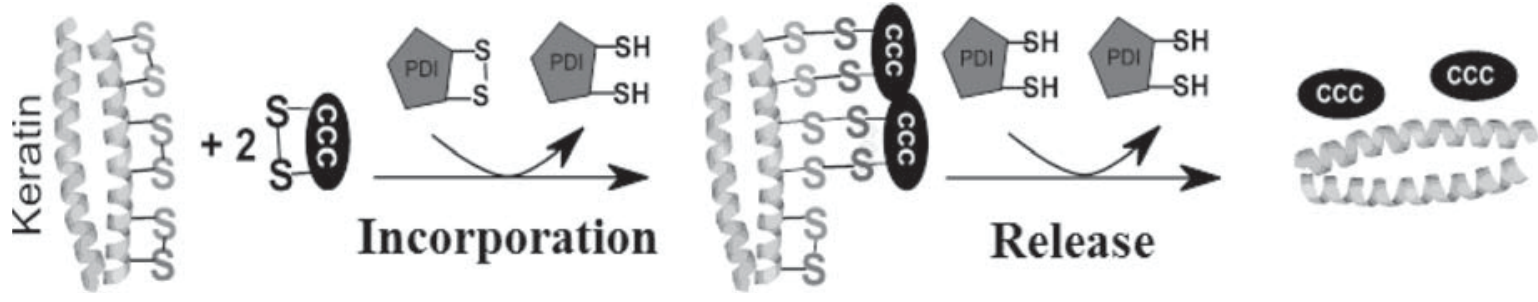

Figure 10. Schematic illustration of the PDI-assisted reactions of cysteine-containing compounds (CCC) on wool.

Recently, PDI was reported to act as an injury response signal that enhances fibrin generation in the wound site via tissue factor activation. The activation was proved to occur via catalysis of thiol-disulphide exchange, thus initiating the blood-clotting cascade at the site of wound damage (Reinhardt et al. 2008). Together with the results mentioned above, this shows that PDI not only can be used as a trigger for release of an active agent, but can also be an active participant in tissue regeneration processes.

The reversible nature of disulphide bond formation may be exploited in several ways for drug delivery (Saito et al. 2003). The presence of a high redox potential difference between the oxidizing extracellular space and the reducing intracellular space makes the disulphide bond intriguing as a potential delivery tool (Saito et al. 2003). In fact, the first drug conjugate that exploits the reversible nature of this unique covalent bond has already been approved for human use (Saito et al. 2003) and an increasing number of drug formulations that incorporate disulphide bonds have been developed (Gosselin et al. 2001; Ishida et al. 2001; Kakizawa et al. 2001; King et al. 1978; McKenzie et al. 2000). Indeed, any active substance that can be incorporated using disulphide bond modulation may be released in this way.

\section{PDI-assisted functionalization of hair}

Human hair has been the subject of a wide range of scientific investigations. Its chemical, physical and biological properties are of importance to the cosmetic industry, forensic scientists and biomedical researchers. However, enzymatic modification has not been extensively reported.

A recent study highlights the PDI-assisted incorporation of cysteine-containing peptides through disulphide bonds on hair, one of which was able to enter into the cortex (Figure 12) (Fernandes \& Cavaco Paulo 2011a; Fernandes et al. 2011b). Besides disulphide bonding, these peptides were expected to restore the mechanical and thermal properties of hair damaged by repeated bleaching.

Bleaching processes are used to lighten the shade of hair by oxidation of pigments (eumelanin and pheomelanin) present in the hair cortex (Gray 2001).
Hydrogen peroxide $\left(\mathrm{H}_{2} \mathrm{O}_{2}\right)$ is used as an oxidizing ingredient in the process, present up to $12 \%$ in alkaline solution (Brown 1997). Despite its cosmetic importance, the chemical damage brought on by bleaching is a major drawback of this commonly used hair-care technique. The oxidation reaction destroys some of the disulphides within the keratin, leading to weakening of the hair structure, high porosity and severe wear of the cuticle layer. To reduce these problems, the incorporation of different peptides on hair assisted by PDI was accomplished after the bleaching treatment. These peptides were developed based on the amino-acid sequence of cuticular keratin type II from human hair (Smith \& Parry 2007; Naeem et al. 2006) and pulmonaryassociated surfactant protein B from mammalian lung (SPB) (Moore et al. 1992; Pilot-Matias et al. 1989) and both were able to increase the hair-fibre robustness. Other studies have reported the use of PDI to perform a curling, waving or straightening treatment safely under mild conditions (Brockway 1992), while a thioredoxin-like compound (fragment of PDI) was used to efficiently treat hair with low amounts of thioglycolic acid, a commonly applied agent in relaxation treatments (Pigiet 1990).

The cosmetic industry is constantly seeking new products to overcome problems brought on by conventionally used hair-care processes. The incorporation

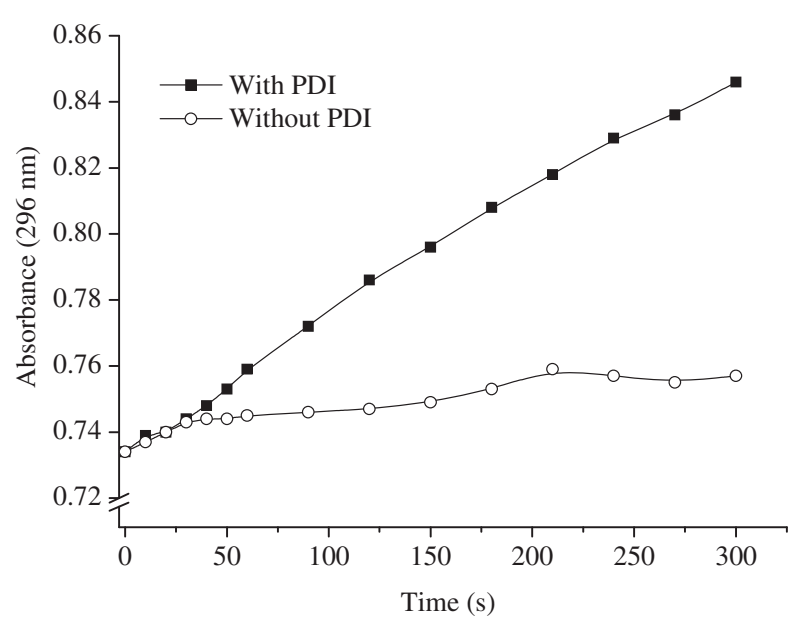

Figure 11. RNase A activity in solution, after being released from the wool surface. 


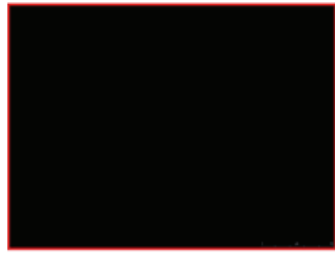

A

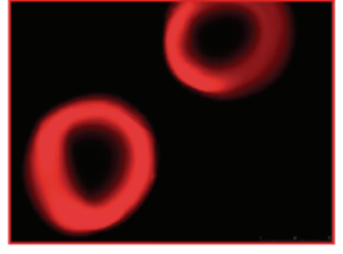

B

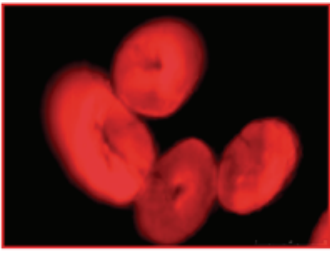

C

Figure 12. Fluorescence images of cross sections of human hair fibres, at $40 \times$ magnification: (A) control (B) hair fibres treated with a cysteine-containing peptide and (C) hair fibres treated with a cysteine-containing peptide in the presence of PDI.

of enzymes in hair formulations has yet to be thoroughly investigated but may constitute an interesting approach for the development of a completely new area of modern hair-care products. The presence of a high content of cysteine residues in hair makes PDI a strong candidate for these applications. The creation of stable and strong of disulphide linkages between hair and cysteine containing compounds catalyzed by PDI is certainly an approach to take into consideration.

\section{Acknowledgment}

We thank to FCT 'Fundação para a Ciência e Tecnologia' (scholarship SFRH/BD/38363/2007) for providing Margarida Fernandes the grant for $\mathrm{PhD}$ studies.

Declaration of interest:The authors report no conflicts of interest. The authors alone are responsible for the content and writing of the paper.

\section{References}

Anfinsen CB. 1973. Principles that govern the folding of protein chains. Science181(4096):223-230.

Araújo R, Silva C, Machado R, Casal M, Cunha AnM, Rodriguez-Cabello JC, Cavaco-Paulo A. 2009. Proteolytic enzyme engineering: a tool for wool. Biomacromolecules 10(6): $1655-1661$.

Åslund F, Berndt KD, Holmgren A. 1997. Redox potentials of glutaredoxins and other thiol-disulfide oxidoreductases of the thioredoxin superfamily determined by direct protein-protein redox equilibria. J Biol Chem 272(49):30780-30786.

Barba C, Scott S, Kelly R, Parra JL, Coderch L. 2009. New anionic surface-active agent derived from wool proteins for hair treatment. J Appl Polymer Sci 115(3):1461-1467.

Barbieri L, Battelli MG, Stirpe F. 1982. Reduction of ricin and other plant toxins by thiol:protein disulfide oxidoreductases. Arch Biochem Biophys 216(1):380-383.

Bartlett AI, Radford SE. 2009. An expanding arsenal of experimental methods yields an explosion of insights into protein folding mechanisms. Nat Struct Mol Biol 16(6):582-588.

Bass R, Ruddock LW, Klappa P, Freedman RB. 2004. A major fraction of endoplasmic reticulum-located glutathione is present as mixed disulfides with protein. J Biol Chem 279(7):5257-5262.

Bauhuber S, Hozsa C, Breunig M, Göpferich A. 2009. Delivery of nucleic acids via disulfide-based carrier systems. Adv Mater 21(32-33):3286-3306.
Berisio R, Sica F, Lamzin VS, Wilson KS, Zagari A, Mazzarella L. 2002. Atomic resolution structures of ribonuclease $\mathrm{A}$ at six $\mathrm{pH}$ values. Acta Crystallogr D. 58(3):441-450.

Bhushan B. 2008. Nanoscale characterization of human hair and hair conditioners. Prog Mater Sci 53(4):585-710.

Block RJ, Diana Bolling, Brand FC, Arnold S. 1939. The composition of keratins. The amino acid composition of hair, wool, horn, and other eukeratins. J Biol Chem 128(1):181-186.

Bradbury JH. 1973. The structure and chemistry of keratin fibres. In: Anfinsen CB Jr, Edsall JT, Richards FM(eds). Advances in protein chemistry. vol 27. New York: Academic Press, pp 111-211.

Brandelli A, Daroit D, Riffel A. 2009. Biochemical features of microbial keratinases and their production and applications. Appl Microbiol Biotechnol 85(6):1735-1750.

Brockway BE. 1992. Treatment of hair. United Kingdom Patent EP0272781.

Brown KC. 1997. Hair coloring. In: Johnson DH, Curtis H, Meadows R(eds) Hair and hair care. New York: Marcel Dekker, Inc, pp 191-216.

Bryngelson JD, Onuchic JN, Socci ND, Wolynes PG (eds). (1995) Funnels, pathways, and the energy landscape of protein folding: A synthesis, vol 21. A Wiley Company: Wiley Subscription Services, Inc.

Bulaj G. 2005. Formation of disulfide bonds in proteins and peptides. Biotechnol Adv 23(1):87-92.

Cabral CM, Liu Y, Sifers RN. 2001. Dissecting glycoprotein quality control in the secretory pathway. Trends Biochem Sci 26(10):619-624.

Cavaco-Paulo AM, Silva CJSM. 2007. Formulation containing neck domains and/or carbohydrate recognition domains for cosmetic applications, namely for the treatment of keratin fibres like hair. Portugal Patent WO/2007/136286.

Cavaco Paulo A, Dos Santos MDSCJ. 2006. Treatment of animal hair fibers with modified proteases. United States Patent.

Chivers PT, Prehoda KE, Raines RT. 1997. The CXXC motif: a rheostat in the active site. Biochemistry 36(14):4061-4066.

Cortez J, Bonner PLR, Griffin M. 2004. Application of transglutaminases in the modification of wool textiles. Enzym Microb Technol 34(1):64-72.

Cortez J, Bonner PLR, Griffin M. 2005. Transglutaminase treatment of wool fabrics leads to resistance to detergent damage. J Biotechnol 116(4):379-386.

Creighton TE. 1979. Intermediates in the refolding of reduced ribonuclease A. J Mol Biol 129(3):411-431.

Creighton TE. 1992a. The disulfide folding pathway of BPTI. Science 256:111-113.

Creighton TE. 1992b. What the papers say: protein folding pathways determined using disulphide bonds. BioEssays 14(3):195-199.

Cunnea PM, Miranda-Vizuete A, Bertoli G, Simmen T, Damdimopoulos AE, Hermann S, Leinonen S, Huikko MP, Gustafsson J-Ãk, Sitia R, Spyrou G. 2003. ERdj5, an endoplasmic reticulum (ER)-resident protein containing DnaJ and thioredoxin domains, is expressed in secretory cells or following ER stress. J Biol Chem 278(2):1059-1066. 
Danciulescu C, Nick B, Wortmann FJ. 2004. Structural stability of wild type and mutated $\alpha$-keratin fragments: molecular dynamics and free energy calculations. Biomacromolecules 5(6):2165-2175.

DebBurman SK, Raymond GJ, Caughey B, Lindquist S. 1997. Chaperone-supervised conversion of prion protein to its protease-resistantance form. Proc Natl Acad Sci USA 94(25): 13938-13943.

Dobson C. 2001. Protein folding and its links with human disease. Biochem Soc Symp 68:1-26.

Dybdal Lone (Bagsvaerd, DK), Heine, Elisabeth (Aachen, DE), Hocker, Hartwig (Aachen, DE). 2001. Method for enzymatic treatment of wool. United States Patent.

Edman JC, Ellis L, Blacher RW, Roth RA, Rutter WJ. 1985. Sequence of protein disulphide isomerase and implications of its relationship to thioredoxin. Nature 317(6034):267-270.

Ellgaard L, Ruddock LW. 2005. The human protein disulphide isomerase family: substrate interactions and functional properties. EMBO Rep 6:28-32.

Fassio A, Sitia R. 2002. Formation, isomerisation and reduction of disulphide bonds during protein quality control in the endoplasmic reticulum. Histochem Cell Biol 117(2):151-157.

Fernandes M, Cavaco Paulo A. 2011a. Protein disul? de isomerasemediated grafting of cysteine-containing peptides onto overbleached hair. Biocatal Biotransfor. Available online. doi:10.3109/1 0242422.2012.644436

Fernandes MM, Gomes A, Vasconcelos A, Munteanu F-D, Tzanov T, Gonçalves M, End N, Schoening K-U, Guebitz G, Cavaco-Paulo A. 2011b. Protein disulphide isomerase-assisted functionalization of keratin-based matrices. Appl Microbiol Biotechnol 90(4):1311-1321.

Fernandes MM, Silva R, Ferreira H, Donelli I, Freddi G, CavacoPaulo A. 2011c. Protein disulfide isomerase-induced refolding of sonochemically-prepared ribonuclease A microspheres. J Biotechnol Submitted.

Feughelman M. 1997. Introduction to the physical properties of wool, hair \& other $\alpha$-keratin fibres. In:Feughelman M (ed) Mechanical properties and structure of alpha-keratin fibres: wool, human hair and related fibres. Sidney: UNSW Press, pp $1-14$.

Forster S, Freedman R. 1984 Catalysis by protein disulphideisomerase of the assembly of trimeric procollagen from procollagen polypeptide chains. Biosci Rep 4:223-229.

Franbourg A, Leroy F. 2005. Hair structure, function, and physicochemical properties. In: Bouillon C, Wilkinson J (eds). The science of hair care. New York: CRC Press Taylor \& Francis Group, pp 1-74.

Franbourg A, Hallegot P, Baltenneck F, Toutain C, Leroy F. 2003. Current research on ethnic hair. J Am Acad Dermatol 48(6, Supplement 1):S115-S119.

Frand AR, Kaiser CA. 1999. Ero1p oxidizes protein disulfide isomerase in a pathway for disulfide bond formation in the endoplasmic reticulum. MolCell 4(4):469-477.

Freedman RB. 1995. The formation of protein disulphide bonds. Curr Opin Struc Biol 5(1):85-91.

Fu P, Chen J, Tian Y, Watkins T, Cui X, Zhao B. 2004. Anti-tumor effect of hematopoietic cells carrying the gene of ribonuclease inhibitor. Cancer Gene Ther 12(3):268-275.

Fujii T, Ogiwara D, Arimoto M. 2004. Convenient procedures for human hair protein films and properties of alkaline phosphatase incorporated in the film. Biol Pharmaceut Bull 27(1):89-93.

Gedanken A. 2008. Preparation and properties of proteinaceous microspheres made sonochemically. Chem-Eur J 14(13): 3840-3853.

Gilbert HF, Kruzel ML, Lyles MM, Harper JW. 1991. Expression and purification of recombinant rat protein disulfide isomerase from Escherichia coli. Protein Exp Purif 2(2-3):194-198.
Goldberger RF, Epstein CJ, Anfinsen CB. 1963. Acceleration of reactivation of reduced bovine pancreatic ribonuclease by a microsomal system from rat liver. J Biol Chem 238(2): 628-635.

Gosselin M A, Guo W, Lee R J. 2001. Efficient gene transfer using reversibly cross-linked low molecular weight polyethylenimine. Bioconjugate Chem. 12(6):989-994.

Gough JD, Lees WJ. 2005. Effects of redox buffer properties on the folding of a disulfide-containing protein: dependence upon $\mathrm{pH}$, thiol $\mathrm{pKa}$, and thiol concentration. J Biotechnol 115(3): 279-290.

Gray J. 2001. Hair care and hair care products. Clin Dermatol. 19(2):227-236.

Hadas A, Kautsky L. 1994. Feather meal, a semi-slow-release nitrogen fertilizer for organic farming. Nutr Cycl Agroecosys 38(2):165-170.

Harper JD, Lansbury PT. 1997. Models of amyloid seeding in alzheimer's disease and scrapie: mechanistic truths and physiological consequences of the time-dependent solubility of amyloid proteins. Ann Rev Biochem 66(1):385-407.

Hartl FU, Hayer-Hartl M. 2002. Molecular chaperones in the cytosol: from nascent chain to folded protein. Science 295(5561):1852-1858.

Hatahet F, Ruddock LW. 2009. Protein disulfide isomerase: a critical evaluation of its function in disulfide bond formation. Antioxid Redox Sign 11(11):2807-2850.

Hawkins HC, Freedman RB. 1991. The reactivities and ionization properties of the active-site dithiol groups of mammalian protein disulphide-isomerase. Biochem J 275:335-339.

Heine E, Höcker H. 1995. Enzyme treatments for wool and cotton. Rev Prog Coloration Relat Top 25(1):57-70.

Holmgren A. 1985. Thioredoxin. Ann Rev Biochem 54(1): 237-271

Hoshino M, Tomita S, Abe K, Matsuda Y, Terajima K, Kojima T, Somemiya A, Hirose T, Kira K, Namito Y. 1978. Composition of protein fire extinguishing agent. Japan Patent

Hwang C, Sinskey A, Lodish H. 1992. Oxidized redox state of glutathione in the endoplasmic reticulum. Science 257(5076):1496-1502.

Ishida T, Kirchmeier M J, Moase E H, Zalipsky S, Allen T M. 2001. Targeted delivery and triggered release of liposomal doxorubicin enhances cytotoxicity against human B lymphoma cells. BBA-Biomembranes. 1515(2):144-158.

Jones LN, Simon M, Watts NR, Booy FP, Steven AC, Parry DAD. 1997. Intermediate filament structure: hard [alpha]-keratin. Biophys Chem 68(1-3):83-93.

Jungbauer A, Kaar W. 2007. Current status of technical protein refolding. J Biotechnol 128(3):587-596.

Kakizawa Y, Harada A, Kataoka K. 2001. Glutathione-sensitive stabilization of block copolymer micelles composed of antisense DNA and thiolated poly(ethylene glycol)-block-poly(L-lysine): a potential carrier for systemic delivery of antisense DNA. Biomacromolecules. 2(2):491-497.

Katoh K, Tanabe T, Yamauchi K. 2004. Novel approach to fabricate keratin sponge scaffolds with controlled pore size and porosity. Biomaterials 25(18):4255-4262.

Kim PS, Kwon OY, Arvan P. 1996. An endoplasmic reticulum storage disease causing congenital goiter with hypothyroidism. J Cell Biol 133(3):517-527.

King T, LiY, Kochoumian L.1978. Preparation of protein conjugates via intermolecular disulfide bond formation. Biochemistry-US. 17(8):1499-506.

King RD, Brockway BE. 1992. Treatment of wool materials. United Kingdom Patent EP0276547.

Kittle PAC, (PA). 1998. Composition and method for generating a foam barrier and methods of use thereof. United States Patent. 
Klappa P, Ruddock LW, Darby NJ, Freedman RB. 1998. The $\mathrm{b}$ [prime] domain provides the principal peptide-binding site of protein disulfide isomerase but all domains contribute to binding of misfolded proteins. EMBO J 17(4):927-935.

Koehn H, Clerens S, Deb-Choudhury S, Morton JD, Dyer JM, Plowman JE. 2010. The proteome of the wool cuticle. J Proteome Res 9(6):2920-2928.

Koo EH, Lansbury PT, Kelly JW. 1999. Amyloid diseases: abnormal protein aggregation in neurodegeneration. Proc Natl Acad Sci USA 96(18):9989-9990.

Kortemme T, Darby NJ, Creighton TE. 1996. Electrostatic Interactions in the active site of the $\mathrm{N}$-terminal thioredoxin-like domain of protein disulfide isomerase. Biochemistry 35(46): 14503-14511.

Kulp MS, Frickel E-M, Ellgaard L, Weissman JS. 2006. Domain architecture of protein-disulfide isomerase facilitates its dual role as an oxidase and an isomerase in Ero1p-mediated disulfide formation. J Biol Chem 281(2):876-884.

Kurimoto A, Tanabe T, Tachibana A, Yamauchi K. 2003. Keratin sponge: immobilization of lysozyme. J Biosci Bioeng 96(3):307-309.

Leonidas DD, Chavali GB, Oikonomakos NG, Chrysina ED, Kosmopoulou MN, Vlassi M, Frankling C, Acharya KR. 2003. High-resolution crystal structures of ribonuclease A complexed with adenylic and uridylic nucleotide inhibitors. Implications for structure-based design of ribonucleolytic inhibitors. Protein Sci 12(11):2559-2574.

Li J, Chunyong Wu, douglas A. Wicks, Smith RA, Morgan SE. 2007. Preparation and characterization of keratin coatings for orthopedic implant titanium rods. In: Morgan ES, Havelka OK, Lochhead YR (eds). Cosmetic nanotechnology: polymers and colloids in cosmetics; ACS Symposium Series 961. Washington DC: American Chemical Society, pp 149-162.

Lillig $\mathrm{CH}$, Holmgren A. 2007. Thioredoxin and related molecules-from biology to health and disease. Antioxid Redox Signal 9(1):25-47.

Lundstroem J, Holmgren A. 1993. Determination of the reduction-oxidation potential of the thioredoxin-like domains of protein disulfide-isomerase from the equilibrium with glutathione and thioredoxin. Biochemistry 32(26):6649-6655.

Lyles MM, Gilbert HF. 1991. Catalysis of the oxidative folding of ribonuclease A by protein disulfide isomerase: dependence of the rate on the composition of the redox buffer. Biochemistry-US 30(3):613-619.

Lyles MM, Gilbert HF. 1994. Mutations in the thioredoxin sites of protein disulfide isomerase reveal functional nonequivalence of the $\mathrm{N}$ - and C-terminal domains. J Biol Chem 269(49):30946-30952.

Matousek J, Gotte G, Pouckova P, Soucek J, Slavik T, Vottariello F, Libonati M. 2003. Antitumor activity and other biological actions of oligomers of ribonuclease A. J Biol Chem 278(26):23817-23822.

Mazzarella RA, Srinivasan M, Haugejorden SM, Green M. 1990. ERp72, an abundant luminal endoplasmic reticulum protein, contains three copies of the active site sequences of protein disulfide isomerase. J Biol Chem 265(2):1094-1101.

Mcdevitt J, Patrick, Winkler J. 1999. A method for enzymatic treatment of wool. United States Patent

McKenzie D L, Kwok K Y, Rice K G. 2000. A potent new class of reductively activated peptide gene delivery agents. J Biol Chem. 275(14):9970-9977.

Moore EC, Reichard P, Thelander L. 1964. Enzymatic synthesis of deoxyribonucleotides. J Biol Chem 239(10):3445-3452.

Moore KJ, D'Amore-Bruno MA, Korfhagen TR, Glasser SW, Whitsett JA, Jenkins NA, Copeland NG. 1992. Chromosomal localization of three pulmonary surfactant protein genes in the mouse. Genomics 12(2):388-393.
Moss J, Stanley SJ, Morin JE, Dixon JE. 1980. Activation of choleragen by thiol: protein disulfide oxidoreductase. J Biol Chem 255(23):11085-11087.

Murkofsky NA, Lamm ME. 1979. Effect of a disulfide-interchange enzyme on the assembly of human secretory immunoglobulin A from immunoglobulin A and free secretory component. J Biol Chem 254(23):12181-12184.

Naeem M, Wajid M, Lee K, Leal SM, Ahmad W. 2006. A mutation in the hair matrix and cuticle keratin KRTHB5 gene causes ectodermal dysplasia of hair and nail type. J Med Genet 43(3):274-279.

Negri AP, Cornell HJ, Rivett DE. 1993. A model for the surface of keratin fibers. Text Res J 63(2):109-115.

Neira JL, Sevilla P, Menéndez M, Bruix M, Rico M. 1999. Hydrogen exchange in ribonuclease $\mathrm{A}$ and ribonuclease $\mathrm{S}$ : evidence for residual structure in the unfolded state under native conditions. J Mol Biol 285(2):627-643.

O’Connor SD, Komisarek KL, Baldeschwieler JD. 1995. Atomic force microscopy of human hair cuticles: a microscopic study of environmental effects on hair morphology. J Investig Dermatol 105(1):96-99.

Onuchic JN, Wolynes PG. 2004. Theory of protein folding. Curr Opin Struct Biol 14(1):70-75.

Parry DAD, Smith TA, Rogers MA, Schweizer J. 2006. Human hair keratin-associated proteins: Sequence regularities and structural implications. J Struct Biol 155(2):361-369.

Pigiet VPNS, (NJ). 1990. Use of thioredoxin, thioredoxin-derived, or thioredoxin-like dithiol peptides in hair care preparations. United States Patent 4894223.

Pille L, Church JS, Gilbert RG. 1998. Adsorption of aminofunctional polymer particles onto keratin fibres. J Colloid Interface Sci 198(2):368-377.

Pilot-Matias TJ, Kister SE, Fox JL, Kropp K, Glasser SW, Whitsett JA. 1989. Structure and organization of the gene encoding human pulmonary surfactant proteolipid SP-B. DNA $8(2): 75-86$.

Plowman JE. 2003. Proteomic database of wool components. J Chromatogr B 787:63-76.

Plowman JE. 2007. The proteomics of keratin proteins. J Chromatogr B 849(1-2):181-189.

Pollard MG, Travers KJ, Weissman JS. 1998. Ero1p: a novel and ubiquitous protein with an essential role in oxidative protein folding in the endoplasmic reticulum. Mol Cell 1(2):171-182.

Puskas JE, Sen MY, Seo KS. 2009. Green polymer chemistry using nature's catalysts, enzymes. J Polymer Sci Part A: Polymer Chem 47(12):2959-2976.

Raines RT. 1998. Ribonuclease A. Chem Rev 98(3):1045-1066. Reinhardt C, von Brühl M-L, Manukyan D, Grahl L, Lorenz M, Altmann B, Dlugai S, Hess S, Konrad I, Orschiedt L, Mackman N, Ruddock L, Massberg S, Engelmann B. 2008. Protein disulfide isomerase acts as an injury response signal that enhances fibrin generation via tissue factor activation. J Clin Investig 118(3):1110-1122.

Riffel A, Brandelli A. 2002. Isolation and characterization of a feather-degrading bacterium from the poultry processing industry. J Ind Microbiol Biotechnol 29(5):255-258.

Rippon J. 1992. The structure of wool. In: Lewis E, Bradford D (eds). Wool dyeing. Bradford: Society of Dyers and Colourists, pp 1-51.

Rothwarf DM, Li Y-J, Scheraga HA. 1998. Regeneration of bovine pancreatic ribonuclease A: identification of two nativelike three-disulfide intermediates involved in separate pathways. Biochemistry 37(11):3760-3766.

Rouse JG, Van Dyke ME. 2010. A review of keratin-based biomaterials for biomedical applications. Materials 3(2):999-1014.

Saito G, Swanson JA, Lee K-D. 2003. Drug delivery strategy utilizing conjugation via reversible disulfide linkages: role and 
site of cellular reducing activities. Adv Drug Deliver Rev 55(2):199-215.

Sevier CS, Kaiser CA. 2002. Formation and transfer of disulphide bonds in living cells. Nat Rev Mol Cell Biol 3(11):836-847.

Sierpinski P, Garrett J, Ma J, Apel P, Klorig D, Smith T, Koman LA, Atala A, Van Dyke M. 2008. The use of keratin biomaterials derived from human hair for the promotion of rapid regeneration of peripheral nerves. Biomaterials 29(1):118-128.

Silva CJ, Prabaharan M, Gübitz G, Cavaco-Paulo A. 2005. Treatment of wool fibres with subtilisin and subtilisin-PEG. Enzym Microb Technol 36(7):917-922.

Silva CJSM, Sousa F, Gubitz G, Cavaco-Paulo A. 2004. Chemical modifications on proteins using glutaraldehyde. Food Technol Biotechnol 42(1):51-56.

Silva CJSM, Zhang Q, Shen J, Cavaco-Paulo A. 2006. Immobilization of proteases with a water soluble-insoluble reversible polymer for treatment of wool. Enzym Microb Technol 39(4):634-640.

Smith TA, Parry DAD. 2007. Sequence analyses of Type I and Type II chains in human hair and epithelial keratin intermediate filaments: promiscuous obligate heterodimers, Type II template for molecule formation and a rationale for heterodimer formation. J Struct Biol 158(3):344-357.

Soucek J, Raines RT, Haugg M, Raillard-Yoon S-A, Benner SA. 1999. Structural changes to ribonuclease $A$ and their effects on biological activity. Comp Biochem Phys C 123(2):103-111.

Steiner RF, De Lorenzo F, Anfinsen CB. 1965. Enzymically catalyzed disulfide interchange in randomly cross-linked soybean trypsin inhibitor. J Biol Chem 240(12):4648-4651.

Swift JA. 1999. Human hair cuticle: biologically conspired to the owner's advantage. J Cosmet Sci 50:23-47.

Tachibana A, Kaneko S, Tanabe T, Yamauchi K. 2005. Rapid fabrication of keratin-hydroxyapatite hybrid sponges toward osteoblast cultivation and differentiation. Biomaterials 26(3): 297-302.

Tan CJ, Tong YW. 2006. Preparation of superparamagnetic ribonuclease A surface-imprinted submicrometer particles for protein recognition in aqueous media. Anal Chem 79(1): 299-306.

Tanabe T, Okitsu N, Yamauchi K. 2004. Fabrication and characterization of chemically crosslinked keratin films. Mater Sci Eng C 24(3):441-446.

Taniyama Y, Seko C, Kikuchi M. 1990. Secretion in yeast of mutant human lysozymes with and without glutathione bound to cysteine 95. J Biol Chem 265(28):16767-16771.

Teale JM, Benjamin DC. 1976. Antibody as an immunological probe for studying the refolding of bovine serum albumin. I. The catalysis of reoxidation of reduced bovine serum albumin by glutathione and a disulfide interchange enzyme. J Biol Chem 251(15):4603-4608.

Thomas PJ, Qu B-H, Pedersen PL. 1995. Defective protein folding as a basis of human disease. Trends Biochem Sci 20(11):456-459.

Varandani PT, Nafz MA. 1970. Enzymatic destruction of immunoreactivity in proinsulin and insulin and activation of their scrambled forms. Arch Biochem Biophys 141(2): 533-537.
Varandani PT, Nafz MA, Chandler ML. 1975. Insulin degradation. XIV. Interaction of insulin analogs, glucagon, growth hormone, vasopressin, oxytocin, and scrambled forms of ribonuclease and lysozyme with glutathione-insulin transhydrogenase (thiol:protein-disulfide oxidoreductase). Dependence upon conformation. Biochemistry 14(10):2115-2120.

Vasconcelos A, Freddi G, Cavaco-Paulo A. 2008. Biodegradable materials based on silk fibroin and keratin. Biomacromolecules 9(4):1299-1305.

Venetianer P, Straub FB. 1963. The enzymic reactivation of reduced ribonuclease. Biochim Biophys Acta 67:166.

Walker KW, Lyles MM, Gilbert HF. 1996. Catalysis of oxidative protein folding by mutants of protein disulfide isomerase with a single active-site cysteine. Biochemistry-US 35(6): 1972-1980.

Wang C-C, Tsou C-L. 1998. Enzymes as chaperones and chaperones as enzymes. FEBS Lett 425(3):382-384.

Wedemeyer WJ, Welker E, Narayan M, Scheraga HA. 2000. Disulfide bonds and protein folding. Biochemistry 39(15): 4207-4216.

Weissman J, Kim P. 1991. Reexamination of the folding of BPTI: predominance of native intermediates. Science 253(5026): 1386-1393.

Welker E, Narayan M, Wedemeyer WJ, Scheraga HA. 2001. Structural determinants of oxidative folding in proteins. Proc Natl Acad Sci USA 98(5):2312-2316.

Wilkinson B, Gilbert HF. 2004. Protein disulfide isomerase. Biochim Biophys Acta 1699(1-2):35-44.

Wilson RH, Lewis HB. 1927. The cystine content of hair and other epidermal tissues. J Biol Chem 73(2):543-553.

Witt D. 2008. Recent developments in disulfide bond formation. Synthesis 2008(16):2491-2509.

Wolfram LJ. 2003. Human hair: a unique physicochemical composite. J Am Acad Dermatol 48:S106-S114.

Wunderlich M, Glockshuber R 1993. Redox properties of protein disulfide isomerase (dsba) from escherichia coli. vol 2. Cold Spring Harbor Laboratory Press. doi:10.1002/pro.5560020503

Wyckoff HW, Hardman KD, Allewell NM, Inagami T, Johnson LN, Richards FM. 1967. The structure of ribonuclease-S at 3.5 A resolution. J Biol Chem 242(17):3984-3988.

Wysocki AP, Mann GV, Stare FJ. 1954. The cystine and methionine Content of the Hair of malnourished children. Am J Clin Nutr 2(4):243-245.

Yamauchi K, Khoda A. 1997. Novel proteinous microcapsules from wool keratins. Colloids Surf B: Biointerfaces 9(1-2): $117-119$

Yamauchi K, Yamauchi A, Kusunoki T, Kohda A, KonishiY. 1996. Preparation of stable aqueous solution of keratins, and physiochemical and biodegradational properties of films. J Biomed Mater Res 31(4):439-444.

Zimek A, Weber K. 2006. The organization of the keratin I and II gene clusters in placental mammals and marsupials show a striking similarity. Eur J Cell Biol 85(2):83-89.

Zoccola M, Aluigi A, Tonin C. 2009. Characterisation of keratin biomass from butchery and wool industry wastes. J Mol Struct 938(1-3):35-40. 